\title{
El proceso de revisión civil en Cuba: despejando la penumbra en torno a su tramitación y tres causales
}

\author{
Liuba Galbán-Rodríguez ${ }^{*}$ \\ Raúl Alejandro Pipa-Núñez ${ }^{*}$
}

\footnotetext{
Magíster en Derecho Civil y de Familia. Profesora auxiliar, Universidad de Oriente, Santiago de Cuba, Cuba.

Correo electrónico:

lgalban@fd.uo.edu.cu

* Licenciado en Derecho. Abogado del Bufete Colectivo N. ${ }^{\circ}$, Santiago de Cuba, Cuba.

Correo electrónico:

raulpipa@scu.onbc.cu
}

Recibido: 26 de julio del 2015

Aprobado: 4 de septiembre del 2015

Cómo citar este artículo: Liuba GalbánRodríguez, Raúl Alejandro Pipa-Núñez. El proceso de revisión civil en Cuba: despejando la penumbra en torno a su tramitación y tres causales. DIXI 23. Abril 2016. Pág. 105. doi: http://dx.doi.org/10.16925/di.v18i23.1294.

\section{Resumen}

Propósito: ofrecer algunas reflexiones acerca de la necesidad de perfeccionar la concepción y tramitación de la revisión civil en Cuba, especialmente en lo relativo a la regulación de tres de sus causales que, a la vez, son de dependencia funcional penal, debido a las dificultades de la práctica jurídica a la hora de lograr su admisión, tramitación y solución. Descripción: se ofrecerán criterios de la doctrina procesal sobre la construcción jurídica de la revisión, en relación con si se trata de un recurso, un procedimiento o un verdadero proceso, con lo que se aprecia falta de unanimidad, situación que ha trascendido al orden legislativo mundial. Se realiza un análisis comparativo de la revisión en los ámbitos procesales cubanos, relativo a las resoluciones judiciales contra las que procede, tras lo cual se evidencia falta de uniformidad de criterios por la práctica judicial del máximo foro. Punto de vista: se dan a conocer propuestas concretas de modificación de ley para su perfeccionamiento, que contribuyen al mejor ejercicio de la praxis jurídica. Conclusión: la revisión es un proceso que guarda indudable relación con el proceso anterior del cual proviene la resolución firme objeto de ella, encaminado a salvaguardar derechos, sirviendo como ultima ratio de realización de la justicia como valor y fin del Derecho.

Palabras clave: auto, causales, justicia, práctica judicial, revisión civil, sentencia. 


\title{
The Civil Review Proceeding in Cuba: Clearing the Darkness Around its Processing and Three Grounds
}

\begin{abstract}
Purpose: to offer some reflections about the need for perfecting the conception and processing of civil review in Cuba, especially in terms of regulation of three grounds that, in turn, are of criminal-functional dependency due to the difficulties of judicial practice at the time of achieving its admission, processing and solution. Description: criteria of procedural doctrine on the legal construction of review are provided regarding whether it is a remedy, a procedure or a true proceeding, which demonstrates a lack of unanimity that has transcended the global legislative order. Point of view: a comparative analysis of review at the Cuban procedural levels regarding judgments against which it proceeds; this shows a lack of uniform criteria by the judicial practice of the maximum forum. Conclusions: concrete proposals for amending the law are made for perfecting it, thus contributing to a better exercise of legal praxis. The review is a proceeding that undoubtedly relates to the previous proceeding from which the resolution subject thereto comes from, aimed at safeguarding rights and serving as ultima ratio of realization of justice as a value and purpose of Law.
\end{abstract}

Keywords: civil review, grounds, order, judgement, judicial practice, justice.

\section{O processo de revisão civil em Cuba: iluminando a penumbra em torno de sua tramitação e três causas}

\section{Resumo}

Propósito: oferecer algumas reflexões acerca da necessidade de aperfeiçoar a concepção e a tramitação da revisão civil em Cuba, especialmente no que diz respeito à regulação de três de suas causas que são de dependência funcional penal, devido às dificuldades da prática jurídica na hora de conseguir sua admissão, tramitação e solução. Descrição: serão oferecidos critérios da doutrina processual sobre a construção jurídica da revisão, quanto a se se trata de um recurso, um procedimento ou um verdadeiro processo, o qual mostra falta de unanimidade, situação que transcendeu a ordem legislativa mundial. Ponto de vista: realiza-se uma análise comparativa da revisão nos âmbitos processuais cubanos, relativos às resoluções judiciais contra as que procede; isso evidencia a falta de uniformidade de critérios pela prática judicial do máximo fórum. Conclusões: chegam-se a propostas concretas de modificação de lei para seu aperfeiçoamento, o que contribui para o melhor exercício da práxis jurídica. A revisão é um processo que tem indubitável relação com o processo anterior do qual provém a resolução firme objeto dela, encaminhado a resguardar direitos, que serve como ultima ratio de realização da justiça como valor e propósito do Direito.

Palavras-chave: revisão civil, causas, auto, sentença, prática judicial, justiça. 


\section{INTRODUCCIÓN}

En el presente siglo, la revisión procesal continúa siendo objeto de reflexión y análisis de la palestra jurídica internacional. No son pocos los procesalistas ${ }^{1}$ que han dedicado páginas enteras de obras a su estudio y reconstrucción. Sin embargo, aún en la actualidad se reflejan inconsistencias alrededor de esta figura en la que, por ejemplo, la falta de unanimidad doctrinal en torno a si considerar la revisión como un recurso, un procedimiento o un proceso ha repercutido en la letra contenida en las legislaciones procesales civiles de numerosos países como España, ${ }^{2}$ Bolivia, ${ }^{3}$ Uruguay $^{4}$ y Colombia, ${ }^{5}$ solo por citar algunos ejemplos. Tampoco se manifiestan convergencias en cuanto a las resoluciones judiciales contra las que procede la revisión, ante cuál tribunal se interpone, quiénes están legitimados, en fin, varias cuestiones que resulta imposible tratar en el presente artículo.

En la arena nacional cubana, ${ }^{6}$ el estudio de la revisión civil, lejos de encontrarse zanjado, todavía

1. Véase: Eduardo José Couture. Estudios DE Derecho Procesal Civil. Tomo I. Ediar. (1946); Juan de Dios Dobal de Mateo. LA REvisión CIviL. Bosch. (1979); Héctor Fix-Zamudio y José Ovalle Fabela. Derecho Procesal. Instituto de Investigaciones Jurídicas de la UNAM. (1991); Víctor Fairén Guillén. Teoría GENERAL DEL Derecho Procesal. Instituto de Investigaciones Jurídicas de la UNAM. (1992); Miguel Ángel Fernández. Derecho Procesal Civil iI. Centro de Estudios Ramón Areces. (1995); Mario Casarino Viterbo. Manual de Derecho Procesal. Derecho Procesal Civil. Tomo iv. $5 .^{\mathrm{a}} \mathrm{ed}$. Editorial Jurídica de Chile. (2002); David Vallespín Pérez. LA REviSIÓN DE LA SENTENCIA FIRME EN EL PROCESO CIVIL. Atelier (2002); Jaime Guasp y Pedro Aragoneses. Derecho Procesal Civil. Tomo II. Parte Especial Procesos Declarativos y de Ejecución. 6. ${ }^{\mathrm{a}}$ ed. Civitas. (2005).

2. Véase artículos 509 al 516 de la Ley 1 de 2000. Ley de Enjuiciamiento Civil de España. Enero 7 de 2000. Disponible en http://www.boe. es/legislacion/codigos/codigo.php?id=040CodigodeLegislacion Procesal\&modo $=1$

3. Véase artículos 284 al 291 de la Ley 439 de 2013. Código Procesal Civil de Bolivia. Noviembre 19 de 2013. Disponible en http://www. unicen.edu.bo/leyes/LEY\%20N\%C2\%BA\%20439-2013.PDF

4. Véase artículos 281 al 292 de la Ley 15.982 de 1989. Código General del Proceso de la República Oriental del Uruguay. Noviembre 20 de 1989. Disponible en http://www.parlamento.gub.uy/htmlstat/pl/ codigos/EstudiosLegislativos/CodigoGeneraldeProceso2014-03 pdf

5. Véase artículos 354 al 360 de la Ley 1564 de 2012. Código General del Proceso de Colombia. Julio 12 de 2012. Disponible en http:// legislacion.vlex.com.co/vid/ley-n-expide-codigo-proceso-dictan391649121

6. Véase Rafael Grillo Longoria. Derecho Procesal Civil. Tomo III. Los medios de impugnación y procesos especiales. Pueblo y Educación. (1985); Pedro R. Camellón Brito y Pedro J. Felipe López. Los procedimientos de revisión civil y laboral. ONBC, Comp. Conferencia Jurídica Nacional de la Organización NaCional De Bufetes Colectivos. Ediciones onbC. (1989); requiere de desarrollo y perfeccionamiento, sobre todo desde el punto de vista legislativo, lo cual tiene su incidencia en la propia praxis jurídica actual. Los diferentes ámbitos procesales existentes en el Derecho positivo de Cuba evidencian que, con independencia de que la revisión se trate de una institución que existe en todos ellos, la determinación de si es un proceso o procedimiento, de sus causales, resoluciones contra las que procede, sujetos legitimados y tramitación en general, presentan particularidades de concepción en uno y otro campo procesal.

La falta de uniformidad en la práctica jurídica patria de la Sala de lo Civil y lo Administrativo del Tribunal Supremo, fue lo que inicialmente motivó la necesidad de investigar la situación nacional de la institución. En efecto, este órgano, siguiendo la letra del artículo 641 de la vigente Ley Procesal Civil, respecto a que solo las sentencias firmes podrán ser examinadas mediante el proceso de revisión, ha declarado inadmisibles demandas en revisión contra un auto definitivo. Sin embargo, en otras ocasiones el mismo foro judicial ha admitido y resuelto procesos de revisión civil establecidos no contra sentencias, sino contra autos definitivos.

Ante este panorama, se formularon varios interrogantes que trascendieron los límites que originariamente alentaron este estudio: ¿ha sido consecuente el legislador cubano al establecer contra cuáles resoluciones judiciales procede la revisión en materia civil, administrativa, laboral y económica? ¿La redacción vigente de tres de las causales previstas en el artículo 642 de la Ley de Procedimiento Civil, Administrativo, Laboral y Económico (LPCALE) satisface la viabilidad y tramitación de la revisión civil en Cuba? ¿Existe congruencia en las legislaciones procesales cubanas en relación con lo que en doctrina se conoce como naturaleza o, mejor, construcción jurídica de la revisión? ¿Es un recurso, un procedimiento o un proceso?

De ahí que el presente artículo de reflexión tiene como propósito fundamentar la necesidad de perfeccionar la regulación de determinadas cuestiones de la tramitación del proceso de revisión civil en Cuba, especialmente de tres de sus causales que a la vez son de dependencia funcional penal: la declaración de falsedad de documento, el perjurio en testigos,

Orlando González García. Naturaleza jurídica de la revisión civil. Revista Jurídica Justicia y Derecho 6. Marzo de 2006; Ivonne Pérez Gutiérrez y Mario Rivero Errico. La revisión en materia civil. CIABo Boletín ONBC 36. Octubre-diciembre de 2009.

7. Véase Ley 7 de 1977. Ley de Procedimiento Civil Administrativo y Laboral. Agosto 19 de 1977; Decreto Ley 241 de 2006. Por el cual se modifica la Ley de Procedimiento Civil Administrativo y Laboral cubana de 1977. Septiembre 27 de 2006. 
y la prevaricación y el cohecho en integrantes de un tribunal. La invocación de estas causales en sede civil requiere necesariamente de la declaración de la existencia de un delito por la jurisdicción penal. Sin embargo, en la práctica persisten escollos a la hora de lograr su admisión por el más alto foro judicial cubano en su tramitación y solución.

Para la obtención de los resultados, se revisaron legislaciones procesales vigentes en Cuba y en otros países en materia de revisión civil, además de un grupo de textos elaborados por la doctrina sobre el tema en cuestión, tanto patria como procedente del Derecho comparado. De ahí que las reflexiones están orientadas a ofrecer criterios de los más versados procesalistas, en torno a la construcción jurídica de la revisión. También se realiza un atinado análisis comparativo de todos los ámbitos procesales cubanos, en relación con las resoluciones judiciales contra las que procede la iniciación de la revisión. Por último, se exponen los criterios de los autores de este artículo con respecto a la formulación de las comentadas causales contenidas en el precepto $642 \mathrm{de}$ la ley procedimental civil. De esta manera, se obtienen propuestas de pautas para la modificación de la legislación involucrada, con el objeto de contribuir al perfeccionamiento de su redacción, interpretación y aplicación por parte de los operadores del Derecho cubanos. Todo lo cual permitirá un mejor ejercicio de la práctica jurídica nacional actual.

\section{CONTRASTE TEÓRICO EN TORNO}

\section{A LA CONSTRUCCIÓN JURÍDICA DE LA REVISIÓN CIVIL}

La naturaleza jurídica o, mejor, la construcción jurídica $^{8}$ de la revisión civil, es una cuestión que aún no

8. Hay autores que consideran incorrecto utilizar el término de naturaleza jurídica de cualquier institución o rama del Derecho, ya que se estaría asumiendo una concepción esencialista del lenguaje, teniendo en cuenta la carga emotiva del término, y se estaría perdiendo de vista la vaguedad, la ambigüedad y lo inequívoco que puede resultar en ocasiones el uso de este término en diferentes contextos históricos. Es decir, una misma institución o rama del Derecho puede ser valorada de diferentes formas en dependencia de la época de que se trate y del desarrollo social. De otra parte, por la denominación naturaleza jurídica puede entenderse que se está aludiendo al Derecho Natural desarrollado en siglos anteriores, cuyo contenido en nada tiene que ver con lo que se quiere representar cuando es utilizado. Por lo tanto, los autores de este artículo coinciden con aquellos autores que plantean lo acertado de utilizar otros términos como construcción jurídica o esencia jurídica, en vez de naturaleza jurídica. Cf. Ángela Aparisi. Introducción al concepto encuentra unanimidad de criterios entre los autores de la doctrina procesal, y la cual con el devenir del tiempo se torna cada vez más compleja. Ni siquiera se logra coincidir en lo cardinal para su estudio: si es un recurso, un procedimiento o un verdadero proceso.

En el orden legislativo mundial, existen leyes adjetivas civiles que emplean un sin número de denominaciones, cuyos presupuestos parten, fundamentalmente, de criterios teóricos en torno a los límites entre las nociones de proceso y procedimiento. Así, lo designan como "Recurso de Revisión", "Recurso Extraordinario por Infracción Procesal", "Inspección Judicial", "Proceso de Revisión", "Mecanismo de Alta Inspección", "Impugnación de la Cosa Juzgada", "Recursos Excepcionales", "Rescisión de la Cosa Juzgada", "Revocación de la Sentencia Firme", entre otros. $^{9}$

En Cuba, ya desde 1974, la Ley de Procedimiento Civil y Administrativo (LPCA) ${ }^{10}$ reconoció la acción revisoria dentro de un ítem único y autónomo denominado "Proceso de Revisión". Posteriormente, con la promulgación en 1977 de la Ley de Procedimiento Civil, Administrativo y Laboral (LPCAL), se reafirmó la concepción en torno a la denominación. Incluso, con la modificación realizada en el 2006 por el Decreto Ley N. ${ }^{\circ} 241$, se adicionó una cuarta parte, "Del Procedimiento de lo Económico", ${ }^{11}$ introduciendo por primera vez la revisión en esta materia bajo la denominación de "Proceso de Revisión", en el Capítulo Ix, artículos 794 al 798. Sin embargo, lo que resulta desconcertante es que bajo el manto de la

de Derecho. Colectivo de autores. InTRODUcción A LA TeORÍA DEL Derecho. Félix Varela. (2006)

9. Véase: Artículos 65.1 y 72 de la Ley 15.979 de 2012. Código Procesal Civil de la República de Costa Rica. Enero 17 de 2012. Disponible en http://www.universidadcentral.com/wpnew/wpcontent/uploads/2013/07/nuevo_codigo_procesal_civil.pdf; los artículos 544, 547 y 550 en Juan Carlos Cabañas García, Óscar Antonio Canales Cisco y Santiago Garderes. Código Procesal Civil y Mercantil Comentado de la República de El Salvador. Talleres Gráficos. (2010); precepto 691.3 en Juan Miguel Carreras Maraña. Código Procesal Civil Comentado de Honduras. Tegucigalpa. (2008)

10. Véase Ley 1261 de 1974. Ley de Procedimiento Civil y Administrativo. Enero 4 de 1974. Esta ley asumió la denominación de "Proceso de Revisión" en el Libro Séptimo, a partir del artículo 653 , aunque reprodujo virtualmente las mismas cuatro causales que regulaba la anterior Ley de Enjuiciamiento Civil española que rigió en Cuba desde el 1 de enero de 1886. Véase José María Manresa y Navarro. Comentarios a la Ley de Enjuiciamiento Civil Reformada. Tomo v. Reus. (1945).

11. Con lo cual, en adelante, la norma adjetiva civil cubana se denomina Ley de Procedimiento Civil, Administrativo, Laboral y Económico (LPCALE), según así lo dispone el artículo 4 del Decreto Ley 241 de 2006. Véase Decreto Ley 241 de 2006, supra, nota 7. 
ahora vigente LPCALE, el legislador sigue asignando la denominación de "Procedimiento de Revisión" para el ámbito procesal laboral, a pesar de que en lo civil, administrativo y económico acierta en titularlo como "Proceso". Por su parte, en el ordenamiento procesal penal la ley procedimental, en su Libro Sexto, "De los Procedimientos Especiales”, Título viII, regula la revisión en este ámbito en los artículos 455 al 466, nominándolo "Del Procedimiento de Revisión". ${ }^{2}$

Ante la existencia de estas dos acepciones, procedimiento y proceso de revisión, en las arenas procesales cubanas se considera oportuno distinguir entre estos términos. No obstante, se insiste en que en la propia doctrina no se aprecia coincidencia de criterios, y no faltan quienes visualizan la revisión como un recurso.

En efecto, todavía los más acreditados procesalistas del país sostienen posiciones contrapuestas. Los que esgrimen la revisión como un procedimiento son partidarios de este como un recurso más dentro del proceso o, incluso, como un recurso de modo extraordinario. Sustentan su posición en que realmente es un procedimiento de impugnación más dentro de un determinado proceso, puesto que contiene todos los elementos de este medio impugnativo. Además, porque se trabaja con un acto preexistente, es decir, con una materia procedimental ya decidida. El mayor énfasis de esta teoría radica en que dicho acto no puede estimarse proceso, debido a que carece de los elementos autónomos - dígase nuevos sujetos, objeto y fin-, en el propósito de poder ser configurado como independiente, siendo, por el contrario, repetido en la calidad de dichos elementos. Así, el profesor argentino Maier sigue esta tendencia al indicar que la revisión:

Es lo mismo que la casación, una impugnación limitada por sus motivos, pero a contrario de este último recurso, procede por motivos cuyo contenido es, precisamente, inverso al de la casación (...) siempre procede por un - grueso- error en la fijación de los hechos, conforme a un descubrimiento posterior a la sentencia firme impugnada (...) la discusión teórica acerca de si la revisión es un recurso o una acción contra la sentencia no nos ha preocupado: ella es estéril, a partir del hecho de que, sin dudas para nadie, se trata de una impugnación contra la sentencia, por lo que hasta quienes niegan su clasificación entre los recursos precisan una regla que indica la vigencia supletoria de las normas aplicables a ellos. ${ }^{13}$

\footnotetext{
12. Véase Ley 5 de 1977. Ley de Procedimiento Penal. Agosto 13 de 1977.

13. Véase Julio B. J. Maier. Derecho Procesal Penal argentino. Tomo I. Hammurabi SRL. (1989). Pág. 89.
}

En los últimos tiempos, otra parte de la doctrina califica la revisión de resoluciones firmes como una especie de nuevo proceso, la cual tiene por objeto el quebrantamiento de la cosa juzgada, dando supremacía al valor "justicia" por sobre la "seguridad jurídica", constituyendo de esta manera la revisión de resoluciones judiciales definitivas la última exigencia de la justicia. Expresan Guasp y Aragoneses que "la revisión es, por lo tanto, indiscutiblemente, un proceso especial autónomo, aunque tenga indudable relación con el proceso en que emite la resolución judicial recurrida". ${ }^{14}$ Por su parte, expone Gómez Orbaneja que "mientras los recursos propiamente dichos se proponen evitar, la revisión se propone rescindir, y en tanto aquellos inciden en una relación jurídico-procesal aún abierta y que eventualmente prolongan, ésta presupone una relación procesal ya cerrada". ${ }^{15}$

Tratadistas como Prieto Castro, con el fin de no ser parte de las históricas disputas, prefieren hacer alusión al nombre "demanda de revisión". ${ }^{16}$ Otros autores, en aras de no caer en tecnicismos ni correr el riesgo, simplemente proponen no pensar en su naturaleza sino en su objetivo. Así, esgrimen que ninguna consecuencia práctica de relevancia se deriva de adoptar una u otra de las distintas teorías que se proponen para explicarla: "Lo que realmente importa es que la revisión, sea recurso o proceso especial autónomo, consiste en un expediente ideado para combatir en determinados supuestos la eficacia de la cosa juzgada característica de las sentencias firmes". ${ }^{17}$

A tenor de lo reseñado, se considera oportuno establecer las diferencias entre los términos proceso y procedimiento, pues continuamente son confundidos como si fueran sinónimos, cuando existen marcadas diferencias entre ambas categorías. ${ }^{18}$ Incluso, aquellos autores que visualizan la revisión civil como un recurso no siempre se percatan de que lo están asumiendo como un procedimiento.

\footnotetext{
14. Véase Guasp y Aragoneses, supra, nota 1. Pág. 542.

15. Véase Emilio Gómez Orbaneja. Derecho Procesal Civil. Volumen I. Artes Gráficas y Ediciones. (1979). Pág. 461.

16. Véase Leonardo Prieto Castro. Cuestiones de Derecho Procesal. Reus. (1947). Pág. 261.

17. Véase Francisco J. Muñoz Jiménez, et al. Las Salas de Lo Civil y lo Penal de los Tribunales Superiores de Justicia. Centro de Estudios Jurídicos y de Formación Especializada del Departamento de Justicia de la Generalitat de Cataluña. (1994) Págs. 29 y 30.

18. Calamandrei plantea que "los términos proceso y procedimiento, aun empleándose en el lenguaje común como sinónimos, tienen significados técnicos diversos". Véase Piero Calamandrei. Instituciones del Derecho Procesal Civil. Depalma. (1943). Pág. 91.
} 
Históricamente, los procedimientos judiciales consistieron en describir la previsión legal respecto a los actos que debían realizar las partes y el órgano jurisdiccional. Recordando el Derecho romano, la procédure era el conjunto de formas que los ciudadanos debían seguir para obtener justicia y que los tribunales habían de observar para otorgarla. Procedimiento, en este sentido histórico, equivale a forma. El paso dado por los procesalistas consistió en percatarse de que limitándose a describir las distintas formas procedimentales, no se estaba haciendo ciencia, y era preciso hallar un sistema que abarcara la variedad de formas. Surgió así la noción de proceso. ${ }^{19}$

De acuerdo con Montero Aroca et al., "Mientras el proceso es la suma de los actos que se cumplen para la composición de la litis, el procedimiento es el orden o sucesión de su cumplimiento". ${ }^{20}$ Procedimiento hace referencia a forma, a sucesión de actos, y ello sin precisar si esa actividad es la de los órganos jurisdiccionales, pues puede ser también la de los órganos administrativos. ${ }^{21}$ Cuando se habla de procedimiento judicial se está destacando la forma de la actividad judicial, "el lado extremo de la actividad procesal"22, "una consideración meramente formal del proceso"23, o "el fenómeno de la sucesión de actos en su puro aspecto externo". ${ }^{24}$

Aunque proceso y procedimiento tienen una misma raíz etimológica, procedere, en el segundo destaca la nota de actuación externa; mientras que en el primero es necesario tomar en consideración la estructura y los nexos que median entre los actos, los sujetos que los realizan, la finalidad a que tienden, los principios a que responden, las condiciones de quienes los producen, las cargas que imponen y los derechos que otorgan. Mientras existe procedimiento en cualquier actividad jurídica, el proceso es propio y exclusivo de la actuación jurisdiccional..$^{25}$

Resumiendo las ideas planteadas por estos autores, en general, el procedimiento constituye un

19. Véase Juan Montero Aroca, et al. Derecho Jurisdiccional I Parte General. 7. a ed. Tirant lo Blanch. (1997). Pág. 295.

20. Véase Francesco Carnelutti. Sistema de Derecho Procesal. Niceto Alcalá-Zamora Castillo y Santiago Sentís Melendo, trads. Uthea. (1944). Pág. 256.

21. Véase Montero Aroca et al., supra, nota 19. Pág. 293.

22. Véase Leonardo Prieto Castro. Tratado de Derecho

Procesal Civil. Tomo i. Aranzadi. (1985). Pág. 5.

23. Véase Gómez Orbaneja, supra, nota 15. Pág. 14.

24. Véase Andrés De la Oliva Santos. Derecho Procesal Civil. Tomo I. PPU. (1988). Pág. 132.

25. Montero Aroca et al., supra, nota 19. Pág. 294. conjunto de normas que regula la forma en que se realizan actos en un proceso o en parte de este; importa un método propio para la actuación ante los tribunales, comprendiendo una serie de reglas, formas y plazos establecidos por la ley. El proceso, en cambio, es más global, pues está constituido por todos los actos que realizan sucesivamente las partes y el juez, a fin de resolver un conflicto o incertidumbre jurídicos entre las primeras; $y$ para que estos actos tengan eficacia jurídica, deben realizarse de acuerdo con los procedimientos preestablecidos.

El tema sigue siendo discutido en la doctrina, pero los autores de este artículo optan por considerar la revisión como un verdadero proceso. La revisión no supone examinar de nuevo el litigio sobre lo que ha decidido el tribunal ad quo, sino dilucidar el derecho del demandante de revisión sobre la obtención de otra sentencia, que cuando es favorable, es completamente distinta en derecho a la anterior, revocando la que ya se ha juzgado. Además, a diferencia de los recursos que pretenden evitar la firmeza de una resolución, la revisión solo procede contra resoluciones definitivas firmes, es decir, cuando contra ella no se pueda plantear recurso alguno. Lo anterior significa que agotada la vía de recursos - que son oportunidades dentro del mismo proceso- - solo queda abierta la posibilidad de atacar dicha resolución en un nuevo proceso, cumpliendo las causales específicas que lo justifiquen. ${ }^{26}$ De ahí que se visualice la revisión como un proceso autónomo, que guarda indudable relación con el proceso anterior del cual proviene la resolución firme objeto de ella, destinado a lograr su nulidad en los casos excepcionales establecidos por la ley, por un órgano judicial competente e imparcial de jerarquía superior. Está siempre encaminado a salvaguardar los derechos consagrados por el ordenamiento jurídico en cuestión, sirviendo como ultima ratio de realización de la justicia como valor y fin del Derecho. Por tanto, la vigente LPCALE cubana debería encontrar organicidad de criterio legislativo en su Tercera Parte, "Del Procedimiento Laboral", Título Sexto, "Del
26. "La polémica acerca de la naturaleza jurídica de la revisión ha ido evolucionando hacia la concepción moderna de que no se trata de un recurso y, por tanto, resulta inútil tratar de ubicarla entre los ordinarios o extraordinarios, pues los recursos como medios de impugnación de las resoluciones judiciales están destinados para combatir aquellas, cuando aún no han alcanzado firmeza, lo que precisamente se pretende evitar con su interposición; el asunto se encuentra aún sometido al conocimiento del juzgador, mientras que con la revisión se ataca una sentencia o resolución definitiva firme, con fuerza de cosa juzgada. En consecuencia, no cabe duda de que nos encontramos ante un nuevo proceso". Véase González García, supra, nota 6. Pág. 56. 
Procedimiento de Revisión”, modificándose la denominación de este título a: "Del Proceso de Revisión". Así, estaría en franca unidad de concepción sobre la verdadera esencia jurídica de la revisión como proceso, tal como efectivamente se encuentra prevista en todos los demás ámbitos procesales que regula esta ley.

\section{RESOLUCIONES JUDICIALES CONTRA} LAS QUE PROCEDE LA REVISIÓN. CRITERIOS LEGISLATIVOS DISCORDANTES EN LOS ÁMBITOS PROCESALES CIVIL,
ECONÓMICO Y PENAL CUBANO

Uno de los obstáculos que más dificulta la invocación y aplicación de las causales de revisión civil previstas en el artículo 642 de la vigente LPCALE es la resolución judicial que hará lugar a la revisión. Desde el precepto 641, taxativamente se enuncia que será la sentencia firme la única resolución que podrá ser examinada en proceso de revisión. ${ }^{27}$ De esta manera, el legislador omite considerar que no todos los procesos civiles y de familia suelen culminar con una sentencia, pues en muchos casos son los llamados en doctrina y praxis "Autos definitivos" los que deciden la litis.

Por ejemplo, en los procesos sucesorios sobre operaciones divisorias del caudal hereditario la LPCALE, en sus artículos 561 al 563, establece la culminación de dichos procesos mediante auto cuando se logren acuerdos entre los herederos en la junta o cuando ninguno impugne la propuesta del contador partidor. Ya más recientemente y a raíz de la aprobación de determinadas instrucciones del Consejo de Gobierno del Tribunal Supremo Popular, son muchísimos más los procesos que pueden terminar con auto en vez de sentencia. Así, adoptan la forma de autos definitivos aquellos procesos civiles y familiares en los que se logre alcanzar acuerdo entre los litigantes en la comparecencia convocada por el tribunal, en cuyo caso este dictará auto aprobándolo siempre que no contravenga norma de orden público, de naturaleza indisponible. ${ }^{28}$

\footnotetext{
27. Véase Ley 7 de 1977. Ley de Procedimiento Civil Administrativo y Laboral. Artículo 641. Agosto 19 de 1977. Junio de 2004. Las sentencias firmes solo podrán ser examinadas mediante el proceso de revisión en la forma y con las consecuencias que se expresan en los artículos siguientes.

28. Véase Consejo de Gobierno del Tribunal Supremo Popular. Dictamen N. ${ }^{\circ} 162 / 83$ de 1983. Instrucción 216 de 2012. Instrucción 217 de 2012. Instrucción 226 de 2013. Instrucción 216 de 2012. Instrucción 217 de 2012. Instrucción 226 de 2013. Todas aprobadas por el Consejo de Gobierno del Tribunal Supremo Popular de la República de Cuba.
}

¿Qué sucedería, por ejemplo, si existieran documentos que no fueron presentados por mala fe de la contraparte en procesos en los que se dictan dichos autos, y fueran descubiertos con posterioridad a su firmeza documentos que de haberse conocido su existencia hubieran cambiado el resultado final del proceso? ¿Podría incoarse un proceso de revisión contra estos autos? La práctica judicial del Tribunal Supremo Popular en Cuba en sede civil no ha sido uniforme en este sentido, pues en ocasiones siendo consecuentes con la letra del artículo 641 de la LPCALE, han declarado inadmisibles procesos de revisión establecidos contra un auto definitivo, ${ }^{29}$ contrario a momentos que admiten y resuelven procesos de revisión establecidos contra autos, ${ }^{30}$ curiosamente siendo dictadas ambas resoluciones judiciales por parte de los mismos jueces ponentes con solo un mes de diferencia. Esta situación refleja la falta de uniformidad en la práctica jurisdiccional de los más altos magistrados del país. ${ }^{31}$

Los autores de este artículo opinan que el artículo 641 de la LPCALE es muy restrictivo, pues considera la

29. Véase Sala de lo Civil y lo Administrativo del Tribunal Supremo Popular de la República de Cuba. Auto N. $56 / 05$. Noviembre 30 de 2005. Cuyo único considerando expresa: "La promoción establecida al amparo del artículo seiscientos cuarenta y uno de la Ley de Procedimiento Civil no puede ser atendida, toda vez que de su claro texto solo pueden ser examinadas mediante el proceso de revisión las sentencias firmes, en la forma y con las consecuencias que se expresan en los artículos siguientes, condición que no alcanza el Auto número quinientos quince de dos mil dos objeto de la solicitud de revisión".

30. Véase Sala de lo Civil y lo Administrativo del Tribunal Supremo Popular de la República de Cuba. Sentencia No. 11/05. Diciembre 30 de 2005: "CONSIDERANDO: Que por anteriores razonamientos y teniendo en cuenta que entre los objetivos principales de la actividad judicial figura, en primer lugar, el de mantener y reforzar la legalidad socialista, que en el orden judicial el inciso a) del artículo cuatro de la Ley número ochenta y dos de los Tribunales Populares, puesta en vigor el primero de enero de mil novecientos noventa y ocho garantiza, y teniendo en cuenta los principios técnicos configurativos del proceso civil, también se enuncia como el de la bilateralidad de la audiencia, que se basa en que nadie debe ser condenado sin ser oído y vencido en juicio, no cabe duda que procede anularse el Auto noventa y cuatro de treinta de abril del dos mil uno, para que al actor de este proceso participe en él, dio lugar a la señalada resolución judicial, fundamento suficiente para resolver como a continuación se dirá. FALlamos: Declarar Con Lugar (...).” 31. "Lo que no es dable es que se cambie de criterio jurisprudencial, de una sentencia para otra, en un brevísimo periodo de tiempo, incluso por la propia ponente, y sin embargo no se diga la razón motivadora del cambio; esto es, se exponga el por qué no se resuelve como en casos anteriores, o al menos se ofrezca la explicación o razonamiento de por qué se cambia de motivación y de fallo". Véase Leonardo Pérez Gallardo. Algunos criterios jurisprudenciales, en sede sucesoria, de la Sala de lo Civil y Administrativo del Tribunal Supremo. Derroteros del último lustro (2000-2004), Primera Parte. CIABo Boletín ONBC 21.Octubre-diciembre de 2005. Pág. 12. 
sentencia firme como única resolución judicial objeto de revisión. Una situación que bien pudo salvarse en la última modificación realizada a la ley adjetiva en el 2006 por el Decreto Ley N. ${ }^{\circ} 241$. No se entiende cómo es posible que este decreto ley sí prevé para el procedimiento económico la revisión contra sentencias y autos definitivos y firmes, dictados en proceso ordinario por las Salas de lo Económico de los Tribunales Provinciales, así como contra las sentencias dictadas en recursos de casación por la Sala de lo Económico del Tribunal Supremo Popular, según el artículo 794; y no obstante, para la sede civil, la misma ley mantiene luego de su última modificación la situación descrita anteriormente.

Es incomprensible que por medio de un recurso de impugnación sea posible combatir cualquier tipo de resolución judicial, y sin embargo mediante la revisión, cuyo fundamento es precisamente revisar la justicia de un proceso, no se pueda poner en funcionamiento la maquinaria estatal para aquellos asuntos que la propia ley adjetiva en su parte civil prevé que no necesariamente concluyen con una sentencia. En especial en los últimos años en los que, como se explicó, las instrucciones aprobadas por el Consejo de Gobierno del Tribunal Supremo Popular, dan la posibilidad de que numerosos procesos civiles y familiares concluyan con acuerdos conciliatorios recogidos en autos que ponen fin a dichos procesos.

Por su parte, en el ámbito procesal penal, al menos el legislador fue más atinado al estipular en el artículo 455 que podrá promoverse la revisión no solo de sentencias firmes, sino también de autos de sobreseimiento libre. Con ello, el ordenamiento procesal penal cubano se atempera con las más modernas tendencias procesales, las cuales permiten la iniciación de procesos de revisión contra una resolución judicial que no necesariamente adopte la forma de sentencia.

Otros países ${ }^{32}$ incluyen en la procedencia de la revisión no solo la sentencia, y esa es la misma tendencia que recoge el Anteproyecto del Código Procesal Civil Modelo para Iberoamérica. ${ }^{33}$

\footnotetext{
32. Véase Código Procesal Civil de Costa Rica de 2012, supra, nota 9, precepto 72.1. Procedencia y causales: "La revisión procederá contra pronunciamientos que tengan efecto de cosa juzgada material, siempre que concurra alguna de las siguientes causales (...)". 33. Artículo 251. (Procedencia). "El recurso de revisión procede contra las sentencias definitivas o autos interlocutorios ejecutoriados que ponen fin al proceso, dictados por cualquier Tribunal, salvo las excepciones que determine la ley reglamentaria". Véase Secretaría del Instituto Iberoamericano de Derecho Procesal. El Código Procesal Civil. Modelo para Iberoamérica: historia-ANTeCEDENTES-Exposición de Motivos. Instituto Iberoamericano de Derecho Procesal. (1988)
}

Por tanto, somos partidarios del perfeccionamiento de todos los procesos establecidos en las leyes procesales, incluido el proceso de revisión, por constituir una garantía judicial general ${ }^{34}$ para la protección de los derechos reconocidos en la Constitución y las demás leyes; en especial, por ser estos los espacios más utilizados por los ciudadanos en el ordenamiento jurídico cubano. Lo anterior justifica el pronunciarse a favor de la modificación de la LPCALE cubana, al objeto de que se incluya también a los autos definitivos para la procedencia del proceso de revisión en sede civil.

\section{LA FALSEDAD DEL DOCUMENTO,}

\section{EL DELITO DE PERJURIO EN TESTIGOS}

\section{Y LA PREVARICACIÓN O COHECHO}

EN LOS MIEMBROS DE UN TRIBUNAL

\section{COMO CAUSALES QUE DAN LUGAR A LA REVISIÓN CIVIL EN CUBA}

A continuación, se ofrecen algunas reflexiones en torno a tres causales establecidas en el artículo 642 de la LPCALE, las cuales dan lugar a la revisión civil en Cuba. Dichas causales son de dependencia funcional penal, pues requieren necesariamente de la declaración de la existencia de un delito por esa jurisdicción, de manera que puedan dar lugar a la revisión civil.

Artículo 642.-Habrá lugar a la revisión de sentencia firme:

2. Si el fallo se funda en documento que al tiempo de dictarse ignoraba la parte haber sido declarado falso en causa penal o se declarare después la falsedad en dicha forma. ${ }^{35}$

De su redacción se colige que está sujeta a un pronunciamiento en sede penal. Para su alegación en sede civil, no importa el origen o el autor de la falsedad, solo es necesario que esta haya sido declarada

\footnotetext{
34. Cutié Mustelier explica una clasificación de las garantías de los derechos humanos, dentro de la cual se encuentran las garantías judiciales o jurisdiccionales, y dentro de ellas están las generales, que se refirieren a los procedimientos ordinarios (civil, penal, laboral, económico, administrativo), a través de las cuales se protegen varios de los derechos consagrados en la Constitución; así como específicas (ordinarias o extraordinarias). Véase Danelia Cutié Mustelier. El Sistema de Garantías De Los Derechos huma nos en Cuba. Tesis doctoral. Facultad de Derecho, Universidad de Oriente, Santiago de Cuba, Cuba. (1999).

35. Véase Ley 7 de 1977, supra, nota 27.
} 
por un tribunal penal. Tampoco es trascendente si dicha falsedad se declaró antes o después de dictarse la sentencia civil, solo interesa si fue decisiva esa falsedad para el fallo y luego se prueba.

Sin embargo, en la práctica jurídica existen inconvenientes a la hora de tramitar la invocación y aplicación de esta causal, ya que su redacción es terminante en cuanto a que la falsedad tiene que ser declarada en causa penal. Es decir, no se trata solo de que sea sancionado penalmente el autor del documento falso, sino que la sentencia penal debe explícitamente consignar que el documento es falso. Según nuestra experiencia, tal pronunciamiento en la práctica no suele ocurrir en todos los casos. Los tribunales de la jurisdicción penal no llegan siempre a realizar este pronunciamiento en las sentencias (la falsedad del documento en sí). Lo que suele ocurrir es que los magistrados se limitan a juzgar al presunto autor, calificando el delito y sancionando por la falsificación, no declarándose la falsedad del documento en sí en la parte dispositiva de la sentencia, sino que se concentran más bien en sancionar la conducta del que lo falsifica. Así, la declaración de la falsedad del documento en una sentencia penal puede no materializarse, incluso si la persona se sanciona penalmente.

Otra cuestión que llama la atención en relación con esta segunda causal de la revisión civil es que solo se refiere a la declaración de falsedad de documentos, como si este fuese el único medio de prueba susceptible de estar viciado. Es decir, que la restrictiva redacción deja fuera otros medios de prueba tales como los videos u otras reproducciones. La omisión anterior puede estar basada en que en el ordenamiento procesal penal este último medio de prueba no se contempla taxativamente bajo estas denominaciones, sino bajo la concepción de documentos. ${ }^{36} \mathrm{~A}$ diferencia del ordenamiento procesal civil que la prevé en el Libro Segundo, Título II, Capítulo II, "De la Prueba", Sección Sexta "Del Reconocimiento judicial y de las Reproducciones", en el artículo 320 de la LPCALE en relación con el 261.4 (aunque con insuficiencia de regulación), y no en la sección dedicada a regular los documentos y libros. Es decir, las contempla como medios de pruebas diferentes.

\footnotetext{
36. Cf. José I. Cafferata Nores. LA prueba en el proceso PENAL Depalma. (1994). Pág. 65. Por su parte, el autor cubano Pedro Pérez plantea que en el proceso penal el documento "(...) en términos amplios y desde un punto de vista procesal puede definirse como el soporte material que incorpora, mediante signos convencionales, una expresión de pensamiento humano (...)”. Pedro Pérez Pérez. Delitos contra la fe pública. Colectivo de autores. Derecho Penal Especial. Tomo i. Félix Varela. (1997). Pág. 285.
}

Vale apuntar que esta segunda causal también es recogida de manera similar en la Ley de Procedimiento Penal en su artículo 456, apartado 17, para la revisión en este ámbito procesal. Procede cuando "se haya dictado sentencia fundada en documento falso, siempre que este hecho resulte declarado en sentencia firme". ${ }^{37}$

En las dos leyes de la década del 70 , se señaló que procedía la revisión no tan sólo cuando había un documento falso, tal como lo establecía la LECRIM, sino que también procedía cuando hubiesen otras pruebas falsas, de ahí su formulación: (...) la falsedad de las pruebas practicadas (...) Sin embargo, ahora parece retrocederse. Se trata realmente de una modificación sustancial, pues sólo sería admitida la revisión cuando la prueba falsa fuese un documento y se quedarían fuera la falsedad de los otros medios de prueba. ${ }^{38}$

De otro lado, volviendo al análisis de la segunda causal de revisión en el ámbito civil, su redacción discrimina, sin justificación, la nulidad de algún documento que sirvió de sostén al fallo, pero declarada en un proceso civil. Luego de comparar otras legislaciones del orbe, ${ }^{39} \mathrm{es}$ posible aducir que en esta segunda causal se debiera incorporar no solo las falsedades declaradas en juicios penales, sino también aquellas nulidades declaradas por otras jurisdicciones, como las civiles. Limitándose solo a la declaración de falsedad obtenida en materia penal, se pone en desventaja a quien alcanza la declaración de nulidad de un documento en sede civil.

A continuación, se analiza la tercera causal que da lugar al proceso de revisión civil, la cual, al igual que la anterior, tiene una alta dosis de dependencia funcional de la jurisdicción penal.

Artículo 642.-Habrá lugar a la revisión de sentencia firme:

3. Cuando habiéndose dictado en virtud de prueba testifical, los testigos hubieren sido después sancio-

\footnotetext{
37. Véase Ley 5 de 1977, supra, nota 12.

38. Véase Marcelino Díaz Pinillo. El procedimiento penal de revisión. Colectivo de autores. Temas para el estudio del Derecho Procesal Penal. Tomo iII. Félix Varela. (2002). Pág. 108.

39. Por ejemplo, en Bolivia, la redacción de esta causal en el Código Procesal Civil del 2013 no especifica quién emite la declaración de falsedad. Artículo 284. (Procedencia). "Habrá lugar al recurso extraordinario de revisión ante el Tribunal Supremo de Justicia de una sentencia ejecutoriada en proceso ordinario, en los casos siguientes: 1 . Si ella se hubiere fundado en documentos declarados falsos por otra sentencia ejecutoriada que se hubiere dictado con posterioridad a la sentencia que se tratare de rever". Véase Ley 439 de 2013, supra, nota 3.
} 
nados por perjurio y su declaración hubiere servido de fundamento a la sentencia. ${ }^{40}$

Esta causal es relativa a otro de los medios probatorios en sede civil: la prueba testifical. No basta por sí solo el conocimiento de declaraciones falsas, sino que hayan sido esas personas sancionadas por ello. Es decir, debe existir también una sentencia penal que declare el delito de perjurio.

Curiosamente, al revisar todas las causales que dan lugar a la revisión en el ámbito procesal penal, se vislumbra que el artículo 456 de la Ley de Procedimiento Penal no contiene un apartado en específico para regular la posibilidad de que se abra una revisión, en aquellos casos en los cuales existieron testigos que hubieren sido después sancionados por el delito de perjurio y su declaración hubiere servido de fundamento a la sentencia cuya revisión se pretendiese.

En cuanto a la tercera causal del precepto $642 \mathrm{de}$ la ley procedimental civil, si se presta atención a su redacción, se ve cómo excluye la actuación dolosa de un perito. De ahí que no falta quienes en la práctica jurídica cubana consideran que debería incorporarse en la ley adjetiva civil, además de la falsedad en las declaraciones de los testigos, la falsedad de la declaración de los peritos. Esto porque a pesar del valor que le fija la ley en cuanto a la no obligatoriedad de los jueces de sujetarse al dictamen pericial, este medio de prueba goza de buena estima por los magistrados, y generalmente tiene el mayor peso en el debate y, por ende, en el fallo.

En el Derecho comparado, algunos legisladores (como el español) contemplan taxativamente que procede la revisión si los peritos hubieren sido condenados por falso testimonio, dado en las declaraciones que sirvieron de fundamento a la sentencia. ${ }^{41}$ Esta formulación no puede aplicarse en Cuba, debido a que en nuestro ordenamiento jurídico procesal civil los peritos no declaran en los procesos civiles, sino que más bien presentan dictámenes escritos, en conformidad con lo establecido en el artículo 311 de la LPCALE. Sin embargo, el Código Penal cubano sí estipula la posibilidad de que un perito sea sancionado por el delito de perjurio, en su artículo 155.1:

40. Véase Ley 7 de 1977, supra, nota 27.

41. Véase Ley de Enjuiciamiento Civil de España, supra, nota 2: "Artículo 510. (Motivos). Habrá lugar a la revisión de una sentencia firme: 3 Si hubiere recaído en virtud de prueba testifical o pericial, y los testigos o los peritos hubieren sido condenados por falso testimonio dado en las declaraciones que sirvieron de fundamento a la sentencia”,
El que, intencionalmente, al comparecer como testigo, perito o intérprete, ante un tribunal o funcionario competente, preste una declaración falsa o deje de decir lo que sabe acerca de lo que se le interroga, incurre en sanción de privación de libertad de uno a tres años o multa de trescientas a mil cuotas. ${ }^{42}$

De ahí que algunos operadores de la práctica consideran que debe establecerse la posibilidad de que se promueva un proceso de revisión civil, en aquellos casos de peritos sancionados por incurrir en este delito. Otros plantean la conveniencia de iniciar este proceso, ya sea si el perito incurre en el delito de perjurio, como también en el de cohecho. Es decir, no solamente al amparo del aludido artículo 155, apartado 1, sino también del $152,{ }^{43}$ ambos del Código Penal. Fundamentan su opinión tomando como base que en los procesos civiles un perito incurre en la segunda tipicidad más que en la primera, porque no identifican la "declaración falsa" como conducta típica para la calificación del perjurio, el cual según el artículo 155 debe existir específicamente. Estos operadores jurídicos insisten en que es improbable que el perito que intervenga en un proceso civil pueda cometer perjurio, debido a que no ofrece declaraciones, sino un dictamen o informe que emite por exigencia del propio artículo 311 de la

\section{Véase Ley 62 de 1987. Código Penal. Diciembre 29 de 1987. 43. Id. "Artículo 152.1. (Cohecho). 1. El funcionario público que} reciba, directamente o por persona intermedia, para sí o para otro, dádiva, presente o cualquier otra ventaja o beneficio, con el fin de ejecutar u omitir un acto relativo a sus funciones, incurre en sanción de privación de libertad de cuatro a diez años. 2. Si el hecho consiste en aceptar el ofrecimiento o promesa de dádiva, presente u otra ventaja o beneficio, la sanción es de privación de libertad de dos a cinco años o multa de quinientas a mil cuotas o ambas. 3. Si el funcionario a que se refiere el apartado 1 exige o solicita la dádiva, presente, ventaja o beneficio, la sanción es de privación de libertad de ocho a veinte años. 4 . El que dé dádiva o presente o favorezca con cualquier otra ventaja o beneficio, o le haga ofrecimiento o promesa a un funcionario para que realice, retarde $\mathrm{u}$ omita realizar un acto relativo a su cargo, incurre en sanción de privación de libertad de dos a cinco años o multa de quinientas a mil cuotas o ambas. 5. En iguales sanciones incurre el que, con el carácter de perito o auditor, realice los hechos descritos en los apartados anteriores. 6 . Si los hechos descritos en los apartados 1, 2 y 3 se realizan por un empleado público, las sanciones aplicables son las previstas, respectivamente en esos apartados, pero el tribunal podrá rebajarlas hasta la mitad de sus límites mínimos si las circunstancias concurrentes en el hecho o en el autor lo justifican. 7. El funcionario o empleado público que, con abuso de su cargo o de las atribuciones o actividades que le hayan sido asignadas o de la encomienda que se le haya confiado, obtenga beneficio o ventaja personal de cualquier clase, incurre en sanción de privación de libertad de cuatro a diez años, siempre que el hecho no constituya un delito de mayor entidad. 8 . En los casos de comisión de este delito, podrá imponerse además, como sanción accesoria, la de confiscación de bienes". 
LPCALE. Sin embargo, no se puede perder de vista que no todos los peritos que comparecen ante la jurisdicción civil pueden ser juzgados por cohecho en sede penal, ya que no todos tienen la condición de funcionario público que le atribuye el artículo 152 del Código Penal al comisor de ese delito. ${ }^{44}$

Teniendo en cuenta los criterios expuestos, sí debería evaluarse legislativamente la posibilidad de denunciar mediante una causal de revisión civil la conducta dolosa de un perito. Si el fallo del proceso cuya revisión se pretenda se fundó en ese dictamen pericial, debería franquearse la vía a fin de revisarlo a tenor del valor justicia, el cual, por demás, constituye el fundamento y la justificación de la existencia del proceso de revisión, como una garantía judicial más de los ciudadanos para la defensa de sus derechos. Lo mismo se recomienda para la revisión en materia penal, pues dentro de las 19 causales previstas en el precepto 456 , ninguna se refiere específicamente a la actuación del perito.

Por último, corresponde analizar la cuarta causal del proceso de revisión civil, que también presenta importantes escollos para su invocación y tramitación en la práctica jurídica cubana actual.

Artículo 642. Habrá lugar a la revisión de sentencia firme:

4. Cuando la sentencia se hubiere dictado por un tribunal cuyos integrantes sean posteriormente san-

44. A fin de determinar si un perito clasifica como tal, debe partirse de lo establecido por el Consejo de Gobierno del Tribunal Supremo Popular en el Dictamen N. ${ }^{\circ} 162 / 83$. (Julio 5 de 1983), al evacuar duda respecto a la definición de funcionarios públicos a los efectos de lo preceptuado en el artículo 281 de la Ley de Procedimiento Civil, Administrativo y Laboral, norma donde se relacionan, genéricamente, los documentos que dicha legislación considera de carácter público, definiendo en el inciso 1 del mencionado artículo que tienen esa categoría, "los autorizados por funcionarios públicos competentes con las formalidades requeridas en la Ley", sin relacionarlos nominalmente. A este respecto, el dictamen expone que para dilucidar si quien emite el documento es o no un funcionario público, hay que apoyarse en la disposición complementaria al Título II del Libro II del Código Penal, artículo 194, el cual textualmente estipula: "A los efectos de este título se entiende por funcionario público toda persona que tenga funciones de dirección o que ocupe un cargo que implique responsabilidad de custodia, conservación o vigilancia en Órganos Públicos, Institución Militar Oficina del Estado, Empresa o Unidad de Producción de Servicio". El dictamen concluye estableciendo que resulta materialmente imposible confeccionar una relación nominal de los documentos considerados de carácter público, por lo que se reputarán como tales aquellos que reúnan los requisitos establecidos en el artículo 281, inciso 1, de la Ley de Procedimiento Civil, Administrativo y Laboral, atendiendo a la persona que lo emite, al ámbito de sus facultades, al cumplimiento de los requisitos formales de carácter legal y finalmente al contenido de este. cionados por prevaricación o cohecho cometido al dictar dicha sentencia o haberse obtenido ésta por violencia ejercida sobre ellos. ${ }^{45}$

Es admirable la intención del legislador en su afán de penalizar y hacer justicia ante estos lamentables supuestos. No obstante, estamos ante una cuestión de muy difícil prueba, no solo por la probidad que caracteriza a la magistratura cubana posrevolucionaria, sino también porque el precepto contiene una redacción muy amplia: "en plural". Si se hace una lectura literal, se infiere que todos los jueces sean procesados y sancionados por prevaricación o cohecho, 0 que se haya obtenido la sentencia por violencia sobre todos ellos. Al estar redactado en plural, no se hace distinción de aquellos jueces que sin llegar a constituir la totalidad, incurrieron en los mencionados delitos.

"Hasta el momento, no hemos tenido noticias de que se haya establecido en la práctica un proceso de revisión civil al amparo de este motivo"46. Puede ser que nunca haya existido desde la vigencia de la Ley Procesal Civil una situación que mereciera denunciarse bajo esta causal, pero lo cierto es que la manera en que está redactada puede también haber frustrado ese empeño si se hubiese intentado.

Realmente, tal situación se salvaría si se modificara la redacción de esta causal, en el sentido de que se accedería a la revisión cuando alguno de los jueces intervinientes sea luego sancionado penalmente por cualquiera de dichos delitos. De hecho, para ser más específicos y más justos, estipular que incluso cuando uno de los jueces haya sido sancionado posteriormente, se podrá acceder a la revisión solo si el voto del juez en cuestión ha sido decisivo para el pronunciamiento de la sentencia.

También existe otro punto que podría suscitar interés. Es innegable que a tenor del precepto legal, solo será causa de revisión la sentencia penal sancionadora de los jueces, es decir que necesariamente tendrá que haber un pronunciamiento condenatorio en sede penal y entonces cabría esta pregunta: ¿qué sucedería si fallecen, devienen inimputables penalmente o abandonan definitivamente el país los jueces que hayan quebrantado alguna de las señaladas normas penales? Algunos autores ${ }^{47}$ consideran que se debería otorgar a la parte perjudicada la posibilidad de demostrar la concurrencia de alguno de estos

\footnotetext{
45. Véase Ley 7 de 1977, supra, nota 27.

46. Véase Ivonne Pérez Gutiérrez y Mario Rivero Errico, supra, nota 6. Pág. 18.

47. Véase Pedro R. Camellón Brito y Pedro J. Felipe López, supra, nota 6. Pág. 308
} 
delitos por otros medios de pruebas, no creyendo justo que se le deje atada de pies y manos. Esta es otra disyuntiva que se puede encontrar aún sin solución en el Derecho positivo cubano.

Hasta este punto es posible apreciar que las tres causales objeto de reflexión en este artículo son de dependencia funcional penal, pues requieren necesariamente de la declaración de la existencia de un delito por esa jurisdicción. O sea, se basan en el accionar penal condenatorio de una conducta trascendente en el ámbito probatorio del proceso civil, administrativo, laboral y económico, cuya sentencia se revisará

Resulta preocupante la posibilidad de extinción de la responsabilidad prevista en el artículo 59 del Código Penal cubano por fallecimiento del acusado, indulto, amnistía y prescripción de la acción penal, entre otras razones. ${ }^{48}$ Autores cubanos se pronuncian alegando que esta formulación limita la oportunidad de revisar una resolución firme, aun estando viciada, si por factores externos completamente ajenos se extinguiese la responsabilidad penal, pese a tipificarse la conducta delictiva. Abogan por la prorrogabilidad de la jurisdicción civil en casos como los aludidos, lo cual le permita declarar al juez actuante, por sí mismo, la existencia del ilícito en que puede fundarse la revisión cuando no quepa hacerlo en lo penal. ${ }^{49}$

No obstante, es necesario considerar con atención esta última propuesta, ya que habría entonces que analizar otras consecuencias derivadas de las categorías de jurisdicción y competencia, que conllevarían incluso modificaciones a la vigente LPCALE en la parte en la que regula estas cuestiones. Los autores de este artículo se inclinan más bien por perfeccionar la redacción de las tres causales analizadas que dan lugar a la revisión civil en Cuba.

48. Véase Ley 62 de 1987, supra, nota 40: "Artículo 59. La responsabilidad penal se extingue: (a) por muerte del reo; (b) por haber cumplido la sanción impuesta; (c) por haber transcurrido el periodo de prueba correspondiente a la remisión condicional de la sanción; (d) por amnistía; (e) por indulto; (f) por sentencia absolutoria dictada en procedimiento de revisión; (g) por prescripción de la acción penal; (h) por prescripción de la sanción; (i) por desistimiento del querellante en los delitos perseguibles sólo a instancia de parte; (j) por el desistimiento del denunciante en los delitos en que así se disponga en la Parte Especial de este Código; (1) por la expulsión del territorio nacional del extranjero sancionado, en el caso a que se refiere el apartado 3 del artículo 46".

49. Véase Ivonne Pérez Gutiérrez y Mario Rivero Errico, supra, nota 6. Pág. 20.

\section{Conclusiones}

La construcción jurídica de la revisión civil es una cuestión que aún no encuentra unanimidad de criterios entre los autores de la doctrina procesal, en cuanto a si se trata de un recurso, un procedimiento o un verdadero proceso. Esta disparidad doctrinal ha traído como consecuencia que en el orden legislativo mundial existen leyes adjetivas que emplean un sin número de denominaciones. Los autores de este artículo consideran la revisión como un proceso autónomo, que guarda indudable relación con el proceso anterior del cual proviene la resolución firme objeto de ella, destinado a lograr su nulidad en los casos excepcionales establecidos por la ley, por un órgano judicial competente e imparcial de jerarquía superior. Está encaminado a salvaguardar derechos, sirviendo como ultima ratio de realización de la justicia como valor y fin del Derecho.

En el Derecho positivo cubano, los ámbitos procesales existentes conciben la revisión de manera diversa; en el campo penal y laboral, se regula bajo la denominación de procedimiento, mientras que en el civil, administrativo y económico, como proceso. Ello evidencia que en el ámbito procesal patrio no existe uniformidad legislativa en cuanto a la esencia jurídica de la revisión.

El artículo 641 de la LPCALE es restrictivo al considerar la sentencia firme como única susceptible de revisión, como si no existieran procesos civiles y de familia que culminan con autos definitivos. Urge su modificación en aras de salvaguardar la justicia, poniéndose la ley adjetiva civil en consonancia con los ámbitos procesales penal y económico que sí prevén la procedencia de la revisión contra determinadas resoluciones judiciales que adoptan la forma de autos.

Las tres causales analizadas que dan lugar a la revisión civil requieren de la declaración de existencia de un delito por la jurisdicción penal, pero cuando dicha declaración no es materializada, se paraliza la posibilidad de revisar la probable injusticia que subyace en el proceso objeto de revisión. También la manera en que están redactadas limita generalmente su admisión por el alto foro judicial cubano, e incluso deben incluirse otras situaciones no previstas como la actuación dolosa de un perito, cuyo dictamen trascienda al fallo de la sentencia cuya revisión se pretenda. 


\section{REFERENCIAS}

Andrés De la Oliva Santos. Derecho Procesal Civil. Tomo I. PPU. (1988).

Ángela Aparisi. Introducción al concepto de Derecho. Colectivo de autores. InTroducción a LA TeORÍA DEL Derecho. Félix Varela. (2006).

Consejo de Gobierno del Tribunal Supremo Popular de Cuba. Dictamen N. ${ }^{\circ}$ 162/83 de 1983.

Danelia Cutié Mustelier. El sistema de garantías de los Derechos humanos en Cuba. Tesis doctoral. Facultad de Derecho, Universidad de Oriente, Santiago de Cuba, Cuba. (1999).

David Vallespín Pérez. La Revisión DE LA SENTENCIA FIRME EN EL PROCESO CIVIL. Atelier (2002).

Decreto Ley 241 de 2006. Por el cual se modifica la Ley de Procedimiento Civil Administrativo y Laboral cubana de 1977. Septiembre 27 de 2006.

Eduardo José Couture. Estudios de Derecho Procesal Civil. Tomo I. Ediar. (1946).

Emilio Gómez Orbaneja. Derecho Procesal Civil. Volumen I. Artes Gráficas y Ediciones. (1979).

Francesco Carnelutti. Sistema de Derecho Procesal. Niceto Alcalá-Zamora Castillo y Santiago Sentís Melendo, trads. Uthea. (1944).

Francisco J. Muñoz Jiménez, et al. Las Salas de lo CiviL y lo Penal de los Tribunales Superiores de JusTicia. Centro de Estudios Jurídicos y de Formación Especializada del Departamento de Justicia de la Generalitat de Cataluña. (1994).

Héctor Fix-Zamudio y José Ovalle Fabela. Derecho ProCESAL. Instituto de Investigaciones Jurídicas de la UNAM. (1991).

Ivonne Pérez Gutiérrez y Mario Rivero Errico. La revisión en materia civil. CIABO BOLETÍN ONBC 36. Octubre-diciembre de 2009.

Jaime Guasp y Pedro Aragoneses. Derecho Procesal CiviL. Tomo II. Parte Especial Procesos Declarativos y de Ejecución. 6. ${ }^{\mathrm{a}}$ ed. Civitas. (2005).

José I. Cafferata Nores. LA PRUEba EN EL PROCESO PENAL. Depalma. (1994).

José María Manresa y Navarro. Comentarios a LA Ley de Enjuiciamiento Civil Reformada. Tomo v. Reus. (1945).

Juan Carlos Cabañas García, Óscar Antonio Canales Cisco y Santiago Garderes. Código Procesal Civil y Mercantil Comentado de la República de El SalvaDOR. Talleres Gráficos. (2010).
Juan de Dios Dobal de Mateo. La Revisión Civil. Bosch. (1979).

Juan Miguel Carreras Maraña. Código Procesal Civil Comentado de Honduras. Tegucigalpa. (2008).

Juan Montero Aroca, et al. Derecho Jurisdiccional i Parte General. 7. ${ }^{a}$ ed. Tirant lo Blanch. (1997).

Julio B. J. Maier. Derecho Procesal Penal argentino. Tomo I. Hammurabi SRL. (1989).

Ley 1261 de 1974. Ley de Procedimiento Civil y Administrativo. Enero 4 de 1974. Publicación de Legislaciones. (1974).

Ley 5 de 1977. Ley de Procedimiento Penal. Agosto 13 de 1977. Empresa Gráfica de Granma. (2004).

Ley 7 de 1977. Ley de Procedimiento Civil Administrativo y Laboral. Agosto 19 de 1977.

Ley 62 de 1987. Código Penal. Diciembre 29 de 1987. Empresa Gráfica de Granma. (2004).

Ley 1 de 2000. Ley de Enjuiciamiento Civil de España. Enero 7 de 2000.

Ley 15.982 de 1989. Código General del Proceso de la República Oriental del Uruguay. Noviembre 20 de 1989.

Ley 15.979 de 2012. Código Procesal Civil de la República de Costa Rica. Enero 17 de 2012.

Ley 1564 de 2012. Código General del Proceso de Colombia. Julio 12 de 2012.

Ley 439 de 2013. Código Procesal Civil de Bolivia. Noviembre 19 de 2013.

Leonardo Pérez Gallardo. Algunos criterios jurisprudenciales, en sede sucesoria, de la Sala de lo Civil y Administrativo del Tribunal Supremo. Derroteros del último lustro (2000-2004), Primera Parte. Ciabo Boletín onbC 21. Octubre-diciembre de 2005

Leonardo Prieto Castro. Cuestiones de Derecho ProceSAL. Reus. (1947).

Leonardo Prieto Castro. Tratado de Derecho Procesal Civil. Tomo I. Aranzadi. (1985).

Marcelino Díaz Pinillo. El procedimiento penal de revisión. Colectivo de autores. Temas para el estudio del Derecho Procesal Penal. Tomo iII. Félix Varela. (2002).

Mario Casarino Viterbo. Manual de Derecho Procesal. Derecho Procesal Civil. Tomo iv. 5. ${ }^{a}$ ed. Editorial Jurídica de Chile. (2002).

Miguel Ángel Fernández. Derecho Procesal Civil II. Centro de Estudios Ramón Areces. (1995).

Orlando González García. Naturaleza jurídica de la revisión civil. Revista Jurídica Justicia y Derecho 6. Marzo de 2006. 
Pedro Pérez Pérez. Delitos contra la fe pública. Colectivo de autores. Derecho Penal Especial. Tomo I. Félix Varela. (1997).

Pedro R. Camellón Brito y Pedro J. Felipe López. Los procedimientos de revisión civil y laboral. ONBC, comp. CONFERENCIA JURídica NACIONAL de LA ORganización Nacional de Bufetes Colectivos. Ediciones onbC. (1989).

Piero Calamandrei. Instituciones del Derecho ProceSAL Civil. Depalma. (1943).

Rafael Grillo Longoria. Derecho Procesal Civil. Tomo III. Los medios de impugnación y procesos especiales. Pueblo y Educación. (1985).
Sala de lo Civil y lo Administrativo del Tribunal Supremo Popular de la República de Cuba. Auto N. ${ }^{\circ}$ 56/05. Noviembre 30 de 2005.

Sala de lo Civil y lo Administrativo del Tribunal Supremo Popular de la República de Cuba. Sentencia N. 11/05. Diciembre 30 de 2005.

Secretaría del Instituto Iberoamericano de Derecho Procesal. El Código Procesal Civil Modelo para IbeROAMÉRICA: HISTORIA-ANTECEDENTES-EXPOSICIÓN DE Motivos. Instituto Iberoamericano de Derecho Procesal. (1988).

Víctor Fairén Guillén. Teoría general del Derecho Procesal. Instituto de Investigaciones Jurídicas de la UNAM. (1992). 